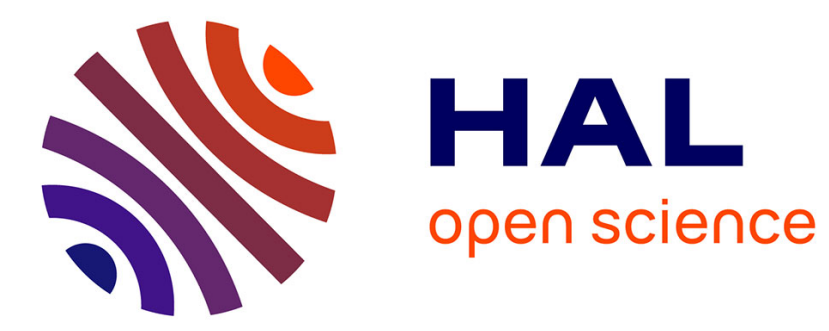

\title{
Localisation of excitation in InGaN epilayers
}

Vyacheslav Kachkanov, Kevin Peter O'Donnell, Sergio Pereira, Robert Martin

\section{To cite this version:}

Vyacheslav Kachkanov, Kevin Peter O'Donnell, Sergio Pereira, Robert Martin. Localisation of excitation in InGaN epilayers. Philosophical Magazine, 2007, 87 (13), pp.1999-2017. 10.1080/14786430701342164. hal-00513828

\section{HAL Id: hal-00513828 \\ https://hal.science/hal-00513828}

Submitted on 1 Sep 2010

HAL is a multi-disciplinary open access archive for the deposit and dissemination of scientific research documents, whether they are published or not. The documents may come from teaching and research institutions in France or abroad, or from public or private research centers.
L'archive ouverte pluridisciplinaire HAL, est destinée au dépôt et à la diffusion de documents scientifiques de niveau recherche, publiés ou non, émanant des établissements d'enseignement et de recherche français ou étrangers, des laboratoires publics ou privés. 


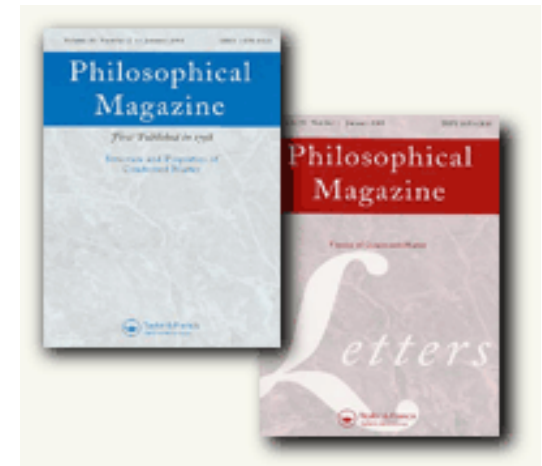

\section{Localisation of excitation in InGaN epilayers}

\begin{tabular}{|c|c|}
\hline Journal: & Philosophical Magazine \& Philosophical Magazine Letters \\
\hline Manuscript ID: & TPHM-06-Jul-0236.R2 \\
\hline Journal Selection: & Philosophical Magazine \\
\hline $\begin{array}{r}\text { Date Submitted by the } \\
\text { Author: }\end{array}$ & 02-Mar-2007 \\
\hline Complete List of Authors: & $\begin{array}{l}\text { Kachkanov, Vyacheslav; Strathclyde University, SUPA Physics } \\
\text { O'Donnell, Kevin; Strathclyde University, SUPA Physics } \\
\text { Pereira, Sergio; Universidade de Aveiro, Fisica } \\
\text { Martin, Robert; Strathclyde University, SUPA Physics }\end{array}$ \\
\hline Keywords: & luminescence, semiconductors \\
\hline Keywords (user supplied): & \\
\hline
\end{tabular}

\section{今 scholaroNE" \\ Manuscript Central}




\title{
Localisation of excitation in InGaN epilayers
}

\author{
V. Kachkanov ${ }^{1}$, K.P. O’Donnell ${ }^{1}$, S. Pereira ${ }^{2}$ and R.W. Martin ${ }^{1}$ \\ ${ }^{1}$ SUPA, Department of Physics, University of Strathclyde, Glasgow, Scotland, UK \\ ${ }^{2}$ CICECO and Departamento de Fisica, Universidade de Aveiro, Aveiro, Portugal
}

\begin{abstract}
Energy scalability of the excitation-emission spectra of InGaN epilayers, quantum wells and light emitting diodes provided indirect evidence for a fundamental common cause of the remarkable optical properties of this commercially important semiconductor alloy. Phase segregation on the nano-scale (accidental quantum dot formation) has generally been accepted as the mechanism of the spectral energy scaling (O’Donnell et al, PRL 82, 237 (1999)). Recently, however, the downsizing of the InN bandgap, from 2 to about $1 \mathrm{eV}$, has prompted a re-examination of the observations. Here, we present new structural evidence of InGaN nanostructure, obtained from a comparative analysis of Ga and In K-edge EXAFS (Extended X-ray Absorption Fine Structure) of a wide range of $\operatorname{In}_{x} \mathrm{Ga}_{1-\mathrm{x}} \mathrm{N}$ epilayer samples. The mean In-Ga and Ga-In next-nearest-neighbour (NNN) separations are found to be unequal in length for InN-poor $(0.1<\mathrm{x}<0.4)$ samples. The degree of inequality increases with decreasing $\operatorname{InN}$ fraction $x$, and therefore correlates with luminescence efficiency in this range of alloy composition. We propose that the breakdown of $\mathrm{In} / \mathrm{Ga}$ randomicity in InGaN alloys is associated with efficient excitation-emission in bluegreen light emitting devices. Although non-randomicity may lead to a weak quasilocalisation of excitation, through the suppression of energy back-transfer, the issue of strong exciton localisation in $\mathrm{InGaN}$ is not directly addressed by these results.
\end{abstract}




\section{INTRODUCTION}

Localisation of excitons by phase segregation ${ }^{1}$ is routinely invoked to explain the high efficiency of InGaN luminescent devices in the face of defect densities much larger than those encountered in other semiconductor materials. The most convincing evidence in support of a correlated spatial and energy localisation of excitons is the micro-spectroscopic observation of a characteristic "spotty" luminescence texture with a length scale of order $100 \mathrm{~nm}$ in PL and CL micrographs of InGaN epilayers ${ }^{2}$.

While electron-hole localisation is widely accepted as a key to enhanced luminescence efficiency in solids, the origin of the localisation mechanism in InGaN is a matter of continuing dispute. Self-formed or 'accidental' InN quantum dots ${ }^{3,4}$ or In-rich (properly, InN-rich) InGaN clusters ${ }^{5,6}$ may act as centres for exciton localisation. However, the discovery of the narrow band gap of $\mathrm{InN}$, recently downsized from 2 to about $1 \mathrm{eV}^{7}$, makes it less likely that pure $\mathrm{InN}$ quantum dots can be solely responsible for InGaN luminescence, since quantum confinement in these structures would have to be very strong to upshift the emission energy by $\sim 2 \mathrm{eV}$ from the $\mathrm{InN}$ band edge to the visible spectral region at which device efficiencies are maximised: pure InN dots with emission near $3 \mathrm{eV}$ necessarily contain only a few In atoms. In experimental terms, the problem of identifying the nano-scale structure of such poorly defined lumophores ("quantum whats") with particular spectral features is very challenging, while the calculation of the spectral signatures of exemplars may lie beyond present theoretical capabilities. Moreover, it is quite difficult to imagine how assemblies (menageries) of small lattice animals with narrow spectral signatures, similar to those identified in spatially resolved photoluminescence experiments $^{8}$, can give rise to a seemingly continuous range of emission energies. 
Transmission Electron Microscopy ${ }^{5}$ (TEM) and Energy Dispersive X-ray (EDX) imaging of InGaN quantum wells ${ }^{6}(\mathrm{QW})$ have claimed to reveal $\mathrm{InN}$-rich clusters, embedded in wells, as distinct contrast spots with a characteristic size of about $3 \mathrm{~nm}$. (Other contributors to this issue will no doubt provide further instances of such observations.) However, both TEM and EDX techniques involve exposure of samples to high-energy ( $100 \mathrm{keV})$ electron bombardment, which may by itself induce phase separation in alloys ${ }^{9,10}$. X-Ray Diffraction (XRD) is another experimental technique that can provide information about phase segregation, if carefully applied. Many authors have reported double (or some higher multiple) XRD peaks in $\theta-2 \theta$ scans, and doublet luminescence peaks in emission spectra, of InGaN epilayers on $\mathrm{GaN}^{11,12}$. These observations were casually ascribed to $\mathrm{InN}$ clustering $^{13}$, but it has since been shown that the attribution of distinct diffraction peaks to separated phases depends upon an incorrect application of Vegard's law which does not take into account the strain state of samples ${ }^{14}$. The joint observation of a luminescence doublet and a split XRD peak can often be better explained by the co-existence of two InGaN layers with the same $\mathrm{InN}$ fraction but different states of strain: one layer at the sample surface is relaxed while the other lies close to the GaN substrate, almost coherent with $\mathrm{it}^{15}$. The so-called "S-shape" of the temperature dependence of the emission peak of InGaN samples has also been described in terms of thermal redistribution of excitons among centres with a range of localisation energies ${ }^{16}$. In certain cases, however, an S-shaped dependence will arise naturally if an unresolved luminescence doublet of the kind described above has components with very different temperature dependences ${ }^{17}$. 
We conclude from the above brief summary that, despite nearly 10 years of effort, no uncontested evidence of a relation between InN-GaN phase segregation and enhanced luminescence efficiency of $\mathrm{InGaN}$ has been obtained in any laboratory. But phase segregation should lead to a characteristic non-randomness in the distribution of cations in a common-anion pseudobinary alloy, and we should exploit experimental techniques that can reveal this. Extended X-ray Absorption Fine Structure (EXAFS) analysis provides a unique structural tool for the acquisition of information about the atomic environment of specific elements in a solid, the socalled local structure ${ }^{18}$. EXAFS is a modulation of the absorption coefficient above a characteristic X-ray absorption edge of the "target" atomic species. It results from the scattering of ejected photoelectrons by atoms in the immediate neighbourhood and their subsequent interference with the outgoing photoelectron wave. EXAFS analysis reveals the chemical nature and coordination number of the surrounding atoms and their radial separation from the central absorber.

Although it provides information about atomic interactions on a subnanometre scale, EXAFS is not a microscopic technique. Microscopies (such as TEM) provide top-down analysis, limited by issues of magnification and resolution, whereas EXAFS offers a bottom-up approach. EXAFS tells us about chemical bonding, co-ordination numbers, bond lengths and so on, working from the nearest to the next nearest neighbours $(\mathrm{NNN})$ and beyond, to build up a "picture" of the average environment of a chosen atomic species in a sample. It is limited by the fact that more distant neighbours interact more weakly with the ejected photoelectron and are therefore less visible. In other words, EXAFS provides statistical information about 
the first few moments of the spatial distribution of near neighbours to a targeted atomic species, e.g. Ga or In, in a solid.

Consider, by way of a guiding example, a "non-random alloy" to be formed artificially by gluing a sample of $\mathrm{InN}$ to an equal one of GaN. Although the $\mathrm{InN}$ fraction of this (very odd) sample will be exactly 50\%, EXAFS on the In sub-lattice will reveal only In atoms in NNN positions, whereas Ga atoms would have all-Ga NNN, according to EXAFS. The degree of phase segregation in such a sample would be estimated as total. Obviously, many other distributions of cation locations could provide the same statistical result within experimental error.

In this contribution we present the first direct measurement of the degree of phase segregation in $\mathrm{InGaN}$ alloys from a detailed analysis that compares the In and Ga local environments for the complete range of $\operatorname{In}_{\mathrm{x}} \mathrm{Ga}_{1-\mathrm{x}} \mathrm{N}$ alloys accessible to the EXAFS technique (roughly $0.1<\mathrm{x}<0.9$ ). We then attempt to relate this statisticalstructural information to the well-known luminescence properties of $\mathrm{InGaN}$ alloy.

\section{SAMPLES AND EXPERIMENTAL DETAILS}

$\mathrm{In}_{x} \mathrm{Ga}_{1-x} \mathrm{~N}$ samples were grown either by Molecular Beam Epitaxy (MBE) or by Metal-Organic Chemical Vapour Deposition (MOCVD). MBE samples with "low" InN contents $(x<0.40)$, and all of the MOCVD samples $(0.1<x \leq 0.4)$, included an InGaN epilayer, some $200-500 \mathrm{~nm}$ thick, grown on a 1-2 $\mu \mathrm{m}$ thick GaN buffer layer on sapphire. InN-rich MBE samples $(x \geq 0.60)$ were grown directly on sapphire substrates without any buffer layers. The $\mathrm{In} / \mathrm{Ga}$ ratio of all layers was measured using wavelength dispersive X-ray (WDX) analysis in a Cameca SX100 Electron Probe Micro-Analyser (EPMA). The intensities of characteristic X-ray emissions from In 
and $\mathrm{Ga}$ in the samples were compared with those from InAs (or InP) and $\mathrm{GaN}$ standards ${ }^{19}$.

EXAFS spectra were measured on stations 7.1 and 16.5 of the UK Synchrotron Radiation Source (SRS) at Daresbury Laboratory. The local structure of In and Ga atoms in InGaN epilayers was probed by means of In K-edge $(27928 \mathrm{eV}$, station 16.5) and Ga K-edge (10370 eV, station 7.1) EXAFS measured in Fluorescence (FLY) and Total Electron Yield (TEY) modes. On station 7.1, a Si(111) double crystal monochromator with sagittally bent second crystal and a nine element monolithic Ge detector were used to measure EXAFS spectra. A Si(200) double crystal monochromator along with a 30-element solid state Ge detector were used to collect EXAFS data on station 16.5. EXAFS measurements in TEY mode were done in a chamber filled with helium. A Keithley 427 amplifier was used to detect current associated with X-ray absorption. TEY probes a thin layer $(\sim 5 \mathrm{~nm})$ close to the sample surface and was chosen for the detection of Ga K-edge absorption in order to avoid any contribution to the InGaN EXAFS signal from Ga atoms located in the buffer. FLY and TEY In K-edge EXAFS was also measured to investigate the possibility of surface segregation. Interatomic distances obtained from the In K-edge EXAFS of InGaN measured in TEY and FLY modes were found to be identical within the measurement error: this preliminary result shows that there are no significant structural differences on a local scale between the bulk of samples and thin layers close to the surface. Therefore, in what follows, In local structure parameters obtained by In K-edge FLY EXAFS will be compared with Ga local structure parameters obtained by Ga K-edge TEY EXAFS. The local structure 
parameters of MBE and MOCVD grown InGaN epilayers are shown Tables I and Tables II respectively.

The model of the local structure used to simulate In or Ga EXAFS was restricted to the two closest atomic coordination spheres that are of greatest interest. (This model is simpler than that used by Blant et al. ${ }^{20}$ and more reliable, since the contribution to EXAFS from nitrogen atoms in the third coordination sphere is rather weak and hard to resolve.) The first coordination sphere always comprised 4 nitrogen atoms. The second coordination sphere was a mixture of In and Ga atoms, with the total number of atoms fixed at 12 . The In-In, Ga-Ga, In-Ga and Ga-In distances were refined separately. The ratio of cationic species (In to $\mathrm{Ga}$ ) in the second coordination sphere was also varied during the fitting procedure to best fit the experimental EXAFS. This ratio serves as a useful check of self-consistency with the independently measured $\mathrm{In} / \mathrm{Ga}$ ratio obtained by EPMA. The fit quality was examined using of the fit index $\mathrm{R}$, which is defined by the expression:

$$
R=\sum_{i}\left[\left(1 /\left(\sigma_{i}\right)\right)(|\operatorname{experiment}(i)-\operatorname{theory}(i)|)\right] \times 100 \%,
$$

where $1 /\left(\sigma_{i}\right)=[k(i)]^{2} /\left(\sum_{i}[k(i)]^{2}|\operatorname{experiment}(i)|\right)$. The validity of extra parameters for each EXAFS simulation was checked using a reduced $\chi^{2}$ method:

$$
\text { reduced } \chi^{2}=\frac{1}{\left(\mathrm{~N}_{\mathrm{i}}-\mathrm{N}_{\mathrm{v}}\right)} \sum_{i}^{N}\left(\frac{X_{\text {data }}\left(k_{i}\right)-X_{\bmod e l}\left(k_{i}\right)}{\varepsilon_{i}}\right)^{2} \text {, }
$$

where $\varepsilon_{i}$ is the uncertainty at each point (assumed to be the same at each point), $X_{\text {data }}$ and $X_{\text {model }}$ are the experimental and model values of the EXAFS at the same point, $\mathrm{N}_{\mathrm{i}}$ is the number of independent points and $\mathrm{N}_{\mathrm{v}}$ is the number of variables used in the fitting. Since in the reduced $\chi^{2}$ test, the assumption is made that the uncertainty is 
the same at each point, the values of reduced $\chi^{2}$ was used for comparison of competing models only. The difference in the parameter values between the best-fit value and the value for which the fit index was increased by $5 \%$ was used to estimate the fitting error. The representative EXAFS spectra and their Fourier Transforms along with simulated data are shown in Fig. 1.

High resolution XRD characterisation was performed on selected samples using a double-crystal diffractometer. The instrumental angular resolution is about 30 seconds of arc. A flat Ge (444) monochromator and horizontal divergence slits with widths of $100 \mu \mathrm{m}$ and a height of $2 \mathrm{~mm}$ were used to select $\mathrm{Cu} \mathrm{K}_{\alpha_{1}}$ radiation. A position sensitive detector was placed at a variable distance from the sample in an achromatic geometry.

\section{RESULTS AND DISCUSSION}

\subsection{EXAFS analysis.}

Mikkelsen and Boyce (MB hereafter) were first to apply EXAFS to local structural studies of semiconductor solid solutions ${ }^{21}$. They discovered that the nearest neighbour (NN) bond lengths in InGaAs, viz. In-As and Ga-As, are similar in magnitude to those of the binary constituents InAs and GaAs respectively but that the weighted average of In-As and Ga-As bond lengths in InGaAs follows Vegard's law. The bimodal distribution of NN bonds and their weak dependence on composition is probably a universal property of pseudobinary alloys ${ }^{22}$ : it has also been observed in $\mathrm{GaAsP}^{23}, \mathrm{CdMnTe}^{24}$ and $\mathrm{ZnMnSe}^{25}$. Concerning the next-nearest neighbour (NNN) separations, i.e. the cation-cation distances, $\mathrm{MB}$ noted that in the absence of clustering, the In-Ga separation (obtained from In-edge EXAFS) and the Ga-In 
separation (obtained from Ga-edge EXAFS) agree with each other very closely throughout the whole composition range of InGaAs alloys. These distances were also found to be closely comparable to the lattice constant, $a$, of the alloys that were obtained from X-ray Diffraction (XRD) measurements which exemplified Vegard's law.

The In-N and Ga-N bond lengths for InGaN alloys are plotted in Fig. 2(a) as a function of $\mathrm{InN}$ fraction. As expected, the distances for all alloys are close to the average NN bond lengths of $\operatorname{InN}(2.15 \AA)$ and GaN (1.95 $)$ ) respectively, and show relatively little variation ( $<5 \%$ overall) with composition, whereas, as shown in Fig. 2(b), the weighted mean of the In-N and Ga-N NN bonds varies linearly between those of the binary constituents, in accordance with Ref. 21. However, when comparing MBE and MOCVD samples of similar InN fraction, we find that the In-N and Ga-N bond lengths are systematically longer in the MOCVD samples. We shall refer to the weighted mean of the In-N and Ga-N distances as the average cationanion distance. For InN-rich MBE samples, the average cation-anion distance coincides with the cation-anion distance predicted by Vegard's law. However, for MBE samples, with $\mathrm{InN}$ fractions below $40 \%$, the average cation-anion distance is significantly smaller than that predicted. For comparable InN-poor MOCVD samples, the average cation-anion distance is somewhat closer to the Vegard's law prediction. These incidental effects, due to strain, have no bearing on the matter of phase segregation and will be discussed later.

In all samples the numbers of In and Ga atoms detected by EXAFS in the second coordination sphere were found to be in agreement with those for a random alloy with the In/Ga composition ratio measured by WDX. This result precludes 
strong clustering of pure InN dots in InGaN alloys. The In-In and In-Ga distances, obtained from In K-edge EXAFS, and the Ga-In and Ga-Ga distances, obtained from Ga K-edge EXAFS, are compared in Fig. 3. In-Ga and Ga-In distances coincide for InN-rich MBE samples ( $x \geq 60 \%$ ), and also for a single MOCVD sample with $40 \%$ InN. However, for MBE and MOCVD samples with less than $40 \% \mathrm{InN}$, the In-Ga and Ga-In separations differ significantly: the mean In-Ga distance is consistently larger than the mean Ga-In distance. This difference in the length of "mixed cation" separations provides a clear indication of a non-random distribution of cations in the sample. In short, this result indicates the existence of InN-rich regions in $\mathrm{InN}$-poor material.

A gross deviation from randomicity in the distribution of cations, leading to different coordination numbers of next-nearest cation neighbours, would indicate the existence of profound clustering or strong phase segregation; this has been found in EXAFS studies of Rare-Earth doped nitrides ${ }^{26,27,28}$, at impurity concentrations as low as a few atomic per cent. In contrast, such large deviations from the random distribution of cations have not been observed for InGaN epilayer samples in this work. However, EXAFS fits have rather large uncertainties for the coordination number (typically $\sim 15 \%$ ). For a smaller degree of phase separation, an alloy could not be distinguished from a random alloy in terms of coordination numbers. On the other hand, the deficit of Ga atoms observed in the average In local structure and the corresponding deficit of In atoms in the average Ga local structure clearly indicates the presence of InN-rich regions (and complementary GaN-rich ones) in our $\mathrm{InN}$ poor samples. Thus, the difference in "mixed cation" distances, reported here, 
indicates $a$ weak phase separation in the form of $\mathrm{InN}$-rich and GaN-rich $\mathrm{InGaN}$ regions, which occurs predominantly at rather low $\operatorname{InN}$ fractions, $\mathrm{x}<0.4$.

Fig. 4 summarises the NNN data related to the difference in "mixed cation" distances on the In and Ga sub-lattices as a function of $\mathrm{InN}$ content. It shows clearly that the difference in separations, i.e. the degree of non-randomness, increases with decreasing InN fraction. The disparity is always higher for MBE than for MOCVD samples with the same InN fraction. The largest measured difference of $0.09 \AA$, corresponding to about $2.8 \%$ of the corresponding lattice constant, is observed for an MBE sample with a global InN fraction of $\sim 27 \%$. The trend for all MOCVD samples and for most MBE samples is clearly that of increasing disparity of the Ga and In sublattices with decreasing $\mathrm{InN}$ fraction.

Since EXAFS tells us nothing directly about the spatial distribution of different phases, it is important to distinguish the effects of In aggregation from those of random compositional disorder on the local scale: in the case of random compositional disorder, the distribution of cations, of whichever kind, is still random and the average local structures of In and Ga will be the same. However in the case of In aggregation, there is a real difference in the In and Ga local structures since on average more In atoms are located in $\mathrm{InN}$-rich regions and more $\mathrm{Ga}$ atoms in $\mathrm{GaN}$ rich regions; this is completely and trivially true for the totally segregated sample presented in the introduction. For real samples, the situation is also quite clear if we understand the limitations of the EXAFS technique.

3.2. Relation to optical properties and XRD. 
We now attempt to reconcile the local structure results described above with what is already known about the optical properties of the examined samples ${ }^{29,30,31,32}$. Firstly, luminescence spectroscopy showed that the peak emission energies of comparable MBE and MOCVD samples were somewhat different: the peak emission energies of MBE samples are always lower that those of MOCVD samples of similar composition $^{29}$. This fact suggests that a higher degree of indium aggregation in MBE samples, compared to MOCVD samples of the same average composition, produces higher local $\mathrm{InN}$ fractions in $\mathrm{InN}$-poor regions, leading to lower emission energies. This clearly links the local structure with the emission properties and solves one mystery.

Next, the Stokes' shift between absorption and emission is largest for samples with an intermediate range of $\mathrm{InN}$ content ${ }^{31,33,34}$, indicating that the highest degree of exciton localisation occurs for this most mixed composition. However, the results presented in this letter show that the In and Ga local structure is the same for In-rich MBE samples $(x \geq 60 \%)$ and for MOCVD InGaN sample with $40 \%$ of InN. In these cases, exciton localisation can result only from compositional disorder in a random alloy: there is no phase segregation in the InN-rich samples. Random disorder cannot be detected by EXAFS since EXAFS provides an averaged picture of the local structure of a particular atom. Therefore, the results of In and Ga local structure studies by means of EXAFS suggest that in InGaN alloys with InN fraction less than $40 \% \mathrm{InN}$, excitons are localised on InN-rich InGaN regions, whereas for InGaN alloys with InN fractions of $40 \%$ and more, exciton localisation is likely to be due to random compositional disorder only. The appearance of $\mathrm{InN}$-rich regions with decreasing $\mathrm{InN}$ fraction compares well with the concurrent increase of InGaN 
emission efficiency ${ }^{35}$ suggesting further that $\mathrm{InN}$-rich $\mathrm{InGaN}$ regions act as efficient exciton localisation and/or emission centres.

Finally, the statistics of phase segregation depends upon both the size and the composition of InN-rich (and corresponding GaN-rich) regions; EXAFS averages local structure configurations and does not distinguish between the two contributions. If, however, the observed difference between the "mixed" cation distances were to equal the difference of $0.36 \AA$ between the lattice constants of $\mathrm{InN}$ and GaN, this would indicate a complete phase separation of $\mathrm{InGaN}$ into $\mathrm{InN}$ and $\mathrm{GaN}$, i.e., in this special case almost all of the In and $\mathrm{Ga}$ atoms would be found in $\mathrm{InN}$ and $\mathrm{GaN}$ phases respectively. (Equivalently, if the "mixed" cation distances were found to be equal in length, there would be no phase separation). In the singular case of a twophase mixture of InN dots and InGaN alloy quantum boxes, a splitting of the metallic shell peak in the Fourier transform of In EXAFS was clearly observed ${ }^{36}$.

Consider a separation into only 2 components by way of illustration. The ratio of the difference in the "mixed" cation bonds to the difference in lattice constants of the binary constituents acts as a metric of the degree of phase segregation in a nonrandom alloy; it is equal to the fraction, F, of In atoms residing in In-rich regions:

$$
F=\frac{d_{I n G a}-d_{G a I n}}{a_{I n N}-a_{G a N}} .
$$

Considering only a two-component mixture, the following relations can be written for the average $\mathrm{InN}$ composition of an alloy, $x_{\text {average }}$ :

$$
\begin{gathered}
x_{\text {average }}=x_{\text {In-poor }}(1-f)+x_{\text {In-rich }} f, \\
f=\frac{F x^{\text {In-poor }}}{(1-F) x^{\text {In-rich }}+F x^{\text {In-poor }},}
\end{gathered}
$$


where $x_{\text {In-rich }}$ is the $\mathrm{InN}$ content of $\mathrm{InN}$-rich regions, $x_{\text {In-poor }}$ is the $\mathrm{InN}$ content averaged over the rest of the material, and $f$ is the filling factor, i.e., the partial volume of the material occupied by the InN-rich regions. Assuming, as an educated guess, that the $\mathrm{InN}$ fraction of the $\mathrm{InN}$-rich phase is $10 \%$ greater than the average content $\left(x_{\text {average }}\right)$, for the sample with highest degree of phase separation $(x=27 \%)$ an estimation using equations (3), (4) and (5) shows that In-rich regions (with $x_{I n-r i c h} \approx$ $30 \%$ ) occupy $\sim 25 \%$ of the total volume of this sample.

In order to compare the short range order probed by EXAFS with long range order, Reciprocal Space Maps (RSM) were measured by High Resolution XRD of MBE samples with average InN contents of 14\%, 27\% and 35\%, as shown in Fig. 5. Analysis of the RSMs reveals that the InGaN epilayer with lowest $\mathrm{InN}$ content is nearly pseudomorphic (i.e. $a_{\operatorname{InGaN}}=a_{\text {GaN }}$ ), whereas samples with higher $\operatorname{InN}$ content are partially relaxed. For the sample with $x=27 \%$, partial phase segregation is inferred from the two InGaN-related diffraction spots (different $c$, but the same $a$ lattice constant) which correspond to regions of different InN content. Recall that the difference in "mixed" cation distances of In and Ga local structures obtained from EXAFS analysis (i.e. the degree of phase separation) was highest for this sample. This may suggest that partial phase separation for this sample reaches the (high) degree necessary for its detection by XRD. Calculations based upon elasticity theory $^{37}$ estimate the $\mathrm{InN}$ fraction of the InN-rich phase to be $x=31 \%$, fortuitously close to the assumed $\mathrm{InN}$ content used for illustrative purposes above.

3.3. Influence of strain on EXAFS and XRD measurements. 
The NNN separations determine the lattice constant $a$ of a semiconductor alloy. In a random ternary alloy $A_{x} B_{1-x} C$ the lattice constant $a$ is the average NNN distance. Since the weighted average of $A-A$ and $B-B$ distances is expected to be close to the length of "mixed" cation $A-B$ and $B-A$ bonds, which should be equal in a random alloy, the "mixed" cation bond length is in fact the lattice constant $a$ of a random alloy, which depends on the alloy composition $x$ according to Vegard's law:

$$
a\left(A_{x} B_{1-x} C\right)=r(A-B)=r(B-A)=x r(A-A)+(1-x) r(B-B) .
$$

In a partially phase-separated alloy the weighted average of "pure" cation-cation distances and that of "mixed" cation-cation distances are expected to be close to the lattice constant $a$ :

$$
a\left(\operatorname{In}_{x} G a_{1-x} N\right)=x r(\operatorname{In}-\operatorname{In})+(1-x) r(G a-G a)=x r(\operatorname{In}-G a)+(1-x) r(G a-\operatorname{In}) .
$$

In the case of dilute InGaN samples with InN fraction less than $15 \%$, for which no In atoms could be fitted to EXAFS of the second coordination sphere, the weighted average of In-Ga and Ga-Ga distances is expected to be close to the lattice constant $a:$

$$
a\left(\operatorname{In}_{x} G a_{1-x} N\right)=x r(\operatorname{In}-G a)+(1-x) r(G a-G a)
$$

The lattice constants $a$ calculated from NNN distances by equations (6), (7) and (8) are shown in Fig. 6. In the case of samples with In-rich and Ga-rich regions the weighted average of "pure" cation-cation bonds or that of "mixed" cation-cation bonds (whichever had smaller fitting errors) was taken to approximate the $a$ lattice 
constant. The $a$ lattice constants obtained by XRD are shown in Fig. 6(a) for comparison. The agreement between EXAFS and XRD is seen to be very good.

For MBE samples the behaviour of the $a$ lattice constant obtained from NNN distances mirrors that of the NN In-N and Ga-N bondlengths described previously. Since Vegard's law does not take into account the strain state of epilayers, such biaxial strain is likely to be the cause of the shrinkage of both NN and NNN distances observed in our samples. The existence of biaxial compressive strain is confirmed by XRD, as shown in Fig. 5. For MOCVD samples, NNN distances shrink due to the strain when the InN fraction exceeds $24 \%$. The strain does not, however, affect NN bond lengths in these samples. We conclude that MBE samples with InN fraction less than $40 \%$ and MOCVD samples with InN fraction less than $25 \%$ are subjected to compressive strain which is higher in MBE samples than in MOCVD ones of the same InN content, whereas the set of In-rich MBE samples is essentially relaxed, due to the extremely large lattice mismatch: the critical thicknesses of InNrich alloys grown directly on sapphire are close to zero. The case of MBE samples where both $\mathrm{NN}$ and NNN distances shrink suggests that compressive strain in the epilayers, imposed by the GaN substrates, is accommodated through both angle and length distortion of cation-anion bonds. NN bonds remain almost unaffected when NNN distances shrink due to strain in MOCVD samples: it is easier to bend bonds than to stretch them, in agreement with theoretical calculations ${ }^{38}$.

\subsection{Excitation-emission efficiency and localisation on a non-random lattice.}

The concluding section of our discussion treats in a somewhat speculative manner possible connections between weak localisation, as related to the weak phase 
segregation reported above, and strong localisation, related to accidental QD formation, in InGaN alloys.

The starting point of the discussion is the excitation-emission model that was first put forward in References 3 and 4. We suppose that photonic or electronic excitation interacts with delocalised excitons in the (weakly) phase-separated alloy InGaN. Luminescence, as always, is related to exciton localisation: if an exciton cannot delocalise within a characteristic lifetime, the consequence is a luminescence event (emission of a photon). Crudely speaking, the delocalised exciton is an excitation of the GaN-rich sublattice, while localised excitons favour the InN-rich sublattice. Energy delocalisation after localisation may be called back-transfer of excitation (from localised to delocalised states). This leads to a decrease in luminescence output if the back-transferred excitation becomes shunted somehow into a non-radiative branch.

The correlation of energy with composition in an alloy leads to an intimate connection between spatial and energy (and therefore momentum) localisation of excitons. In order to assign a definite energy to an exciton, we suppose that it has a finite extent and normalises the portion of lattice with which it interacts; essentially it 'samples' the In/Ga ratio within its volume (another bottom-up method). While it is clear that delocalised excitons have in general rather higher energy than localised ones, it is difficult to know exactly what this means physically. There is a world of difference between a Wannier and a Frenkel exciton. The mean difference in energy between the peak of the emission and the edge of the excitation spectrum is Stokes' shift. 
Luminescence efficiency measures the ratio of the photon emission rate to the total rate of annihilation of delocalised excitons, regarded as quanta of the excitation. For the efficiency to attain its maximum value of unity, (i) excitation must preferentially reach emitting centres (whatever their nature) rather than non-radiative traps and (ii) back-transfer of excitation from emitting centres to delocalised states must be eliminated.

For the first point, we note that the migration of excitation through a lattice is enhanced by percolation. We speculate that the complementarity of the Ga and In sublattices enhances the delivery of excitation to lumophores when the $\mathrm{InN}$ fraction is lower than the percolation threshold. By the same token, excitons localised on InN-rich regions of the lattice will not readily delocalise. Although the movement of excitons through an energy-disordered environment cannot be described simply as hopping of classical particles between lattice points, it may be significant that the percolation threshold defined in this way for the diamond lattice is 0.43 , which corresponds approximately to the $\mathrm{InN}$ fraction separating random from non-random InGaN alloys. (Of course this may also say something about the formation of the alloy itself during growth: it is notable that no MOCVD material with $\mathrm{x}>0.4$ has been reported in the literature.) As for the second point, transfer of excitation, whether forwards or backwards in energy terms, depends strongly upon the distances involved, whether the mechanism is dipole-dipole $\left(\sim \mathrm{r}^{-6}\right)$ or via tunnelling (exponential). In this context we note that the mean forward-transfer distance (Ga-In) is shorter than the back-transfer distance (In-Ga) in strongly luminescent alloys. In this way a small symmetry breaking can have profound consequences. Finally, we call attention to recent results, also not yet well understood, related to the 
ferromagnetism of $\mathrm{GaN}$ doped with $\mathrm{Gd}^{39}$ : in this system too the effects of percolation (of spins) appear to increase as the impurity becomes more dilute.

\section{CONCLUSIONS}

In summary, a difference between In and Ga local structures was observed by EXAFS investigations of certain InGaN epilayers and attributed to weak phase segregation into InN-rich and GaN-rich regions. An estimate of the extent of these regions can be made, with the simplest set of assumptions, but EXAFS provides no information about the spatial distribution or size of InN-rich regions. Remarkably, the degree of the phase separation was found to increase with decreasing $\mathrm{InN}$ fraction $x$ in $\operatorname{In}_{x} \mathrm{Ga}_{1-x} \mathrm{~N}$. This observation correlates with a concurrent increase of luminescence efficiency, suggesting that slightly InN-rich clusters are responsible for efficient exciton localisation and recombination in InGaN light-emitting devices. However, the (possibly spontaneous) formation of $\mathrm{InN}$-richer regions in $\mathrm{InN}$-poorer material remains to be explained in a fundamental way on the basis of an improved understanding of the growth thermodynamics of InGaN alloy.

The authors are grateful to Dr JFW Mosselmans for leading the InGaN EXAFS programme at SRS Daresbury Laboratory, to Dr Benjamin Hourahine for useful discussions, and to Professor Yasushi Nanishi, Professor Enrique Calleja, Dr Ian M. Watson and Dr Wim van der Stricht for providing the samples used in this study. V. Kachkanov acknowledges financial support from the Overseas Research Students Award Scheme, Strathclyde University and Daresbury Laboratory. 
1. Ho, I.H. and Stringfellow. G.B. Solid phase immiscibility in GaInN. Appl. Phys. Lett. 69, 2701-2703 (1996).

2. Low-dimensional Nitride Semiconductors, edited by Bernard Gil, 1st ed. (Oxford University Press, 2002).

3. O'Donnell, K.P., Martin, R.W., Middleton, P.G. Origin of Luminescence from InGaN Diodes. Phys. Rev. Lett. 82, 237-240 (1999).

4. Martin, R.W. et al. Exciton localization and the Stokes' shift in InGaN epilayers. Appl. Phys. Lett. 74, 263-265 (1999).

5. Chichibu, S. et al. Spontaneous emission of localized excitons in InGaN single and multiquantum well structures. Appl. Phys. Lett. 69, 4188-4190 (1996).

6. Narukawa, T. et al. Role of self-formed InGaN quantum dots for exciton localization in the purple laser diode emitting at $420 \mathrm{~nm}$. Appl. Phys. Lett. 70, 981983 (1997).

7. Davydov, V.Yu. et al. Band Gap of Hexagonal InN and InGaN Alloys. Phys. Stat. Sol. (b) 234, 787-795 (2002).

8. Okamoto, K. et al., Confocal microphotoluminescence of InGaN-based lightemitting diodes. J. Appl. Phys. 98, 064503 (2005).

9. Smeeton, T.M. et al. Electron-beam-induced strain within InGaN quantum wells: False indium "cluster" detection in the transmission electron microscope. Appl. Phys. Lett. 83, 5419-5421 (2003). 
10. Li, T. et al., Indium redistribution in an $\mathrm{InGaN}$ quantum well induced by electron-beam irradiation in a transmission electron microscope, Appl. Phys. Lett. 86, 241911-1 - 241911-3 (2005).

11. Feng, S.-W. et al. Thermal annealing effects on an InGaN film with an average indium mole fraction of 0.31. Appl. Phys. Lett. 83, 3906-3908 (2003).

12. Chang, H.J. et al. Direct evidence of nanocluster-induced luminescence in InGaN epifilms. Appl. Phys. Lett. 86, 021911-1-021911-3 (2005).

13. Srinivasan, S., et al. Low Stokes shift in thick and homogeneous InGaN epilayers, Appl. Phys. Lett. 80, 550-552 (2002).

14. O’Donnell, K.P. et al., Structural analysis of InGaN epilayers. J. Phys. C 13, 6977-6991 (2001).

15. Pereira S. et al. Interpretation of double x-ray diffraction peaks from $\mathrm{InGaN}$ layers. Appl. Phys. Lett. 79, 1432-1434 (2001); Pereira, S. et al. Structural and optical properties of InGaN/GaN layers close to the critical layer thickness. Appl. Phys. Lett. 81, 1207-1209 (2002).

16. Cho, Y.-H. et al. "S-shaped" temperature-dependent emission shift and carrier dynamics in InGaN/GaN multiple quantum wells. Appl. Phys. Lett. 73, 1370-1372 (1998).

17 S. Pereira and K.P. O’Donnell, unpublished.

18. Gurman, S.J. Interpretation of EXAFS Data. J. Synchrotron Radiat. 2, 56-63 (1995). 
19. Martin, R.W. et al. Microcomposition and Luminescence of InGaN Emitters. Phys. Stat. Sol. (a) 192, 117-123 (2002).

20. Blant, A.V. et al., EXAFS studies of plasma-enhanced MBE grown Group IIINitrides. Mater. Sci. Eng. B 50, 38-41 (1997).

21. Mikkelsen, J.C., Boyce, J.B. Extended x-ray-absorption fine-structure study of $\mathrm{Ga}_{1-\mathrm{x}} \mathrm{In}_{\mathrm{x}}$ As random solid solutions. Phys. Rev. B 28, 7130-7140 (1983).

22. Martins, J. L. and Zunger, A. Bond lengths around isovalent impurities and in semiconductor solid solutions. Phys. Rev. B 30, 6217-6220 (1984).

23. Wu, Z. et al. Extended x-ray-absorption fine-structure study of $\mathrm{GaAs}_{x} \mathrm{P}_{1-x}$ semiconducting random solid solutions, Phys. Rev. B 48, 8694-8700 (1993).

24. Balzarotti, A. et al. Local structure of ternary semiconducting random solid solutions: Extended x-ray-absorption fine structure of $\mathrm{Cd}_{1-x} \mathrm{Mn}_{x}$ Te. Phys. Rev. B 30, 2295-2298 (1984).

25. Pong, W.-F. et al. Extended x-ray-absorption fine-structure studies of $\mathrm{Zn}_{1-x} \mathrm{Mn}_{x} \mathrm{Se}$ alloy structure. Phys. Rev. B 41, 8440-8448 (1990).

26. Katchkanov, V. et al. Extended X-ray absorption fine structure studies of thulium doped GaN epilayers. Superlattices Microstruct. 36, 729-736 (2004).

27. Katchkanov, V. et al. Extended X-ray Absorption Fine Structure Studies of GaN Epilayers Doped in situ with Er and Eu During Molecular Beam Epitaxy. Mat. Res. Soc. Symp. Proc. 798, Y5.10.1 (2004)

28. Katchkanov, V. et al. Extended X-ray absorption fine structure studies of GaN epilayers doped with Er. Opt. Mater. 28, 785-789 (2006). 
29. Fernandez-Torrente, I. et al. Anomalous composition dependence of optical energies of MBE-grown InGaN, Mat. Res. Soc. Symp. Proc. 798, 673-676 (2003)

30. O'Donnell, K.P. et al. The composition dependence of the $\operatorname{In}_{x} \mathrm{Ga}_{1-x} \mathrm{~N}$ bandgap. $J$. Cryst. Growth 269, 100-105 (2004).

31. Martin, R.W. et al. The composition dependence of the optical properties of InNrich InGaN grown by MBE. Mat. Res. Soc. Symp. Proc. 831, E3.6 (2005).

32. Hernández, S. et al. Raman scattering study of the InGaN alloy across the whole composition range. J. Appl. Phys. 98, 013511-1 - 013511-5 (2005).

33. Kurouchi, M. et al. Growth and properties of In-rich InGaN films grown on (0001) sapphire by RF-MBE. Phys. Stat. Sol. (b) 241, 2843-2848 (2004).

34. Wu, J. et al. Universal bandgap bowing in group-III nitride alloys. Solid State Commun. 127, 411-414 (2003).

35. Mukai, T. Recent progress in group-III nitride light-emitting diodes. IEEE J. Sel. Top. Quantum. Electron. 8, 264-270 (2002).

36. O'Donnell, K.P. et al. In K-edge extended X-ray absorption fine structure of InGaN epilayers and quantum boxes. Mater. Sci. Eng. B 93, 150-153 (2002).

37. Pereira, S. et al. Strain and composition distributions in wurtzite InGaN/GaN layers extracted from x-ray reciprocal space mapping. Appl. Phys. Lett. 80, 39133915 (2002).

38. Kim, K., Lambrecht, W.R.L., Segall, B. Elastic constants and related properties of tetrahedrally bonded BN, AlN, GaN, and InN, Phys. Rev. B 53, 16310-16326 (1996). 
39. Dhar, S et al. Gd-doped GaN: A very dilute ferromagnetic semiconductor with a Curie temperature above 300 K. Phys. Rev. B 72, 245203 (2005). 
Figure 1. $k^{2}$-weighted In K-edge FLY EXAFS (a) and their Fourier Transform Moduli (b) for MBE InGaN epilayers.

Figure 2. In-N and Ga-N bonds (a) and weighted average of In-N and Ga-N bonds (b) as a function of InN fraction. Solid lines are linear fits to the data.

Figure 3. Next-nearest neighbour distances as a function of $\mathrm{InN}$ fraction in MBE (a) and MOCVD (b) samples. Solid lines are linear fits to the data.

Figure 4. Difference between In-Ga distance of In local structure and Ga-In distance of Ga local structure for MBE and MOCVD samples.

Figure 5. Asymmetric reciprocal space maps of GaN and InGaN (10.5) reflections for MBE-grown samples with InN fraction of $13.5 \%$ (a), $27.3 \%$ (b) and $34.9 \%$ (c). The vertical full lines and the tilted dashed lines indicate coherent growth to the GaN buffer and full relaxation, respectively.

Figure 6. The dependence of the lattice constant $a$, calculated from In and Ga local structure parameters, on InN fraction for MBE (a) and MOCVD (b) samples. Solid lines are a linear fits to the data. 
a)
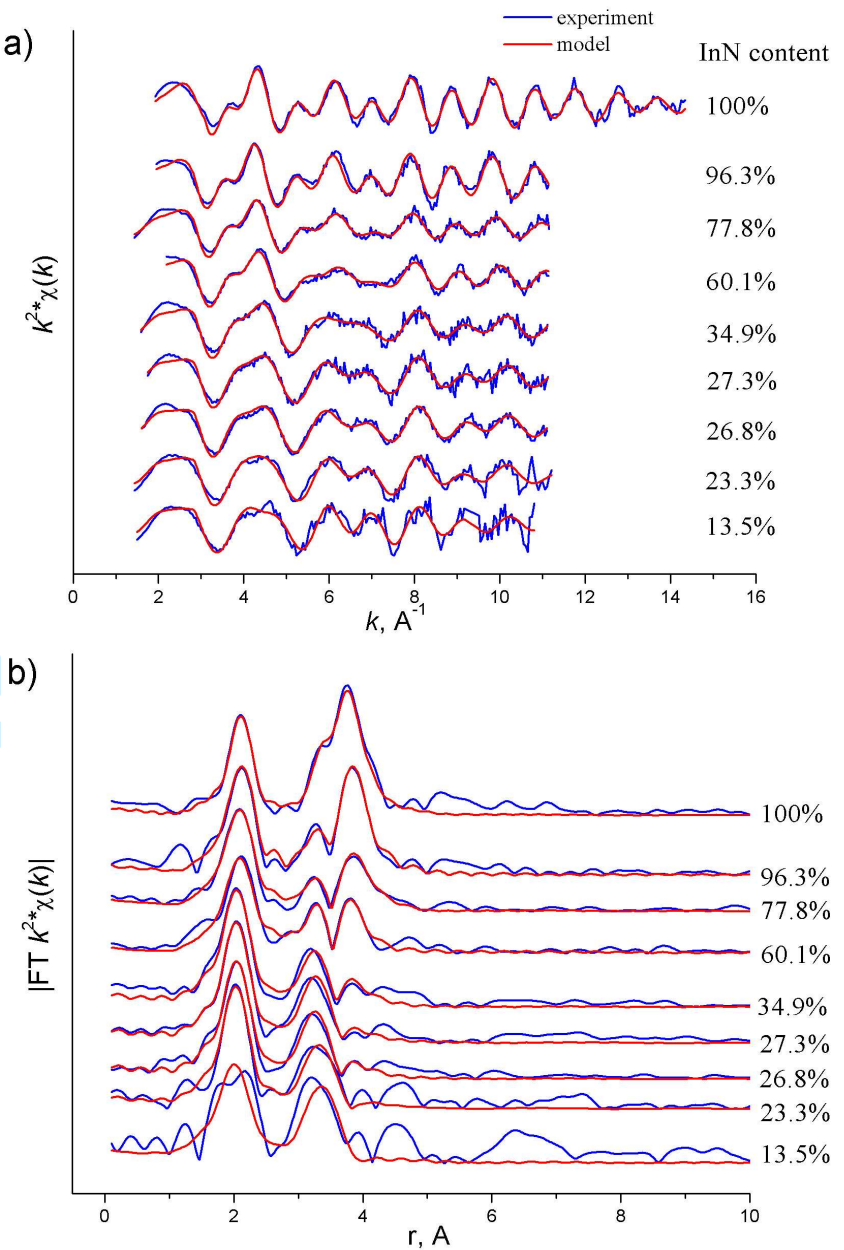

Figure 1. 
a)

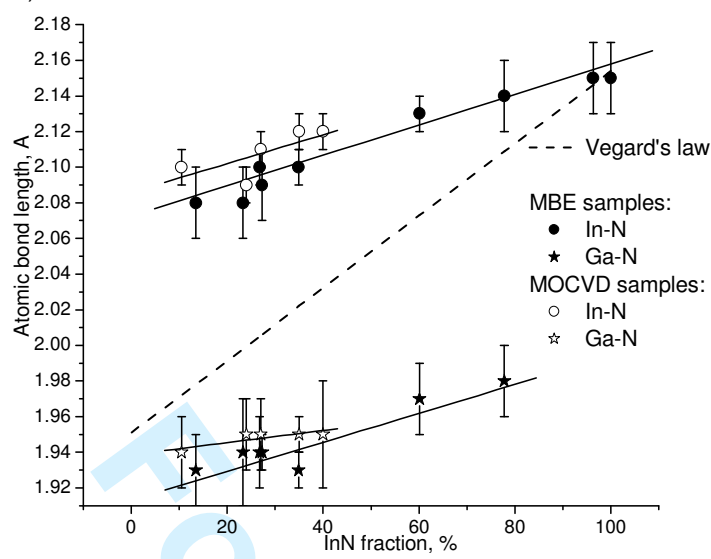

Figure 2.

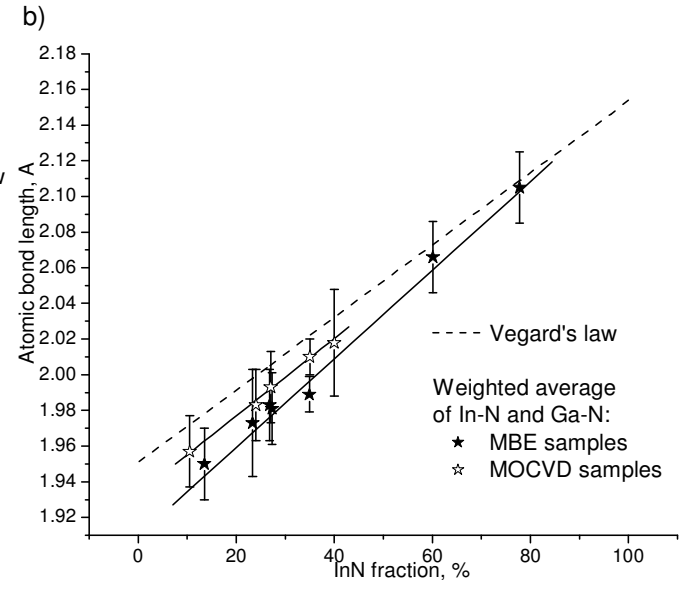



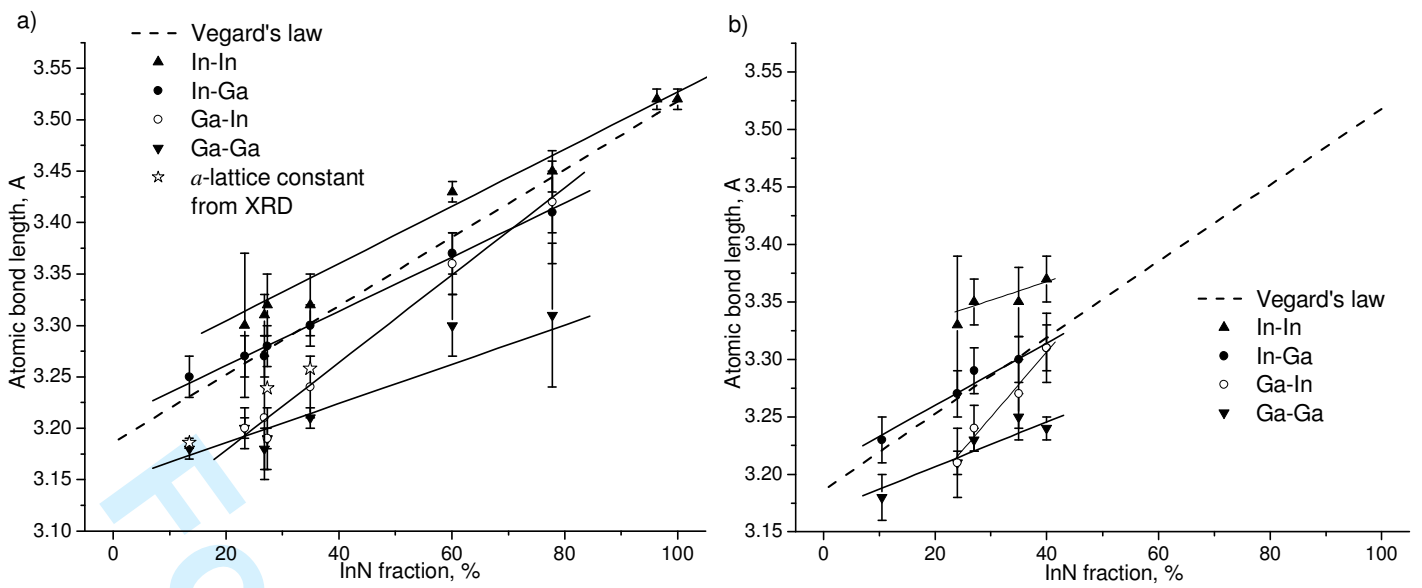

Figure 3. 


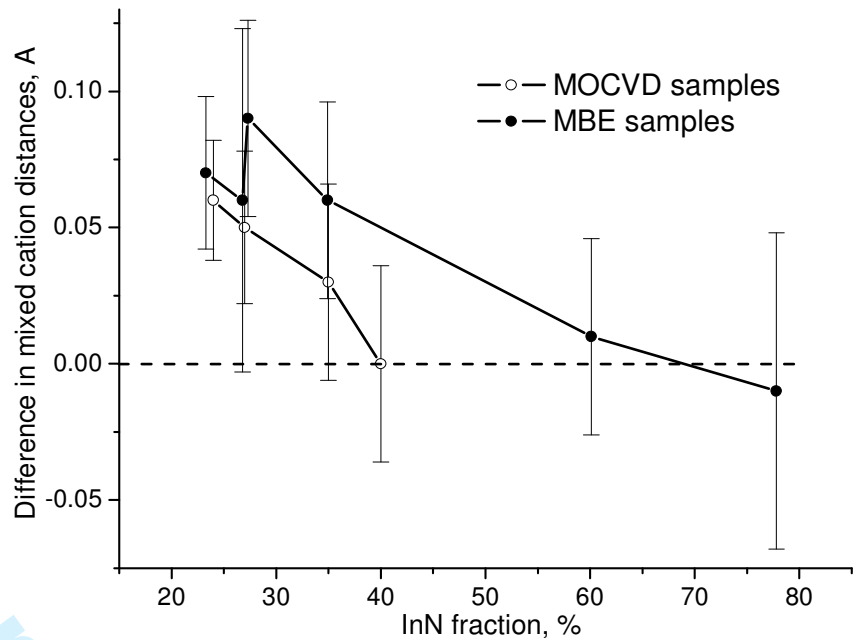

Figure 4. 


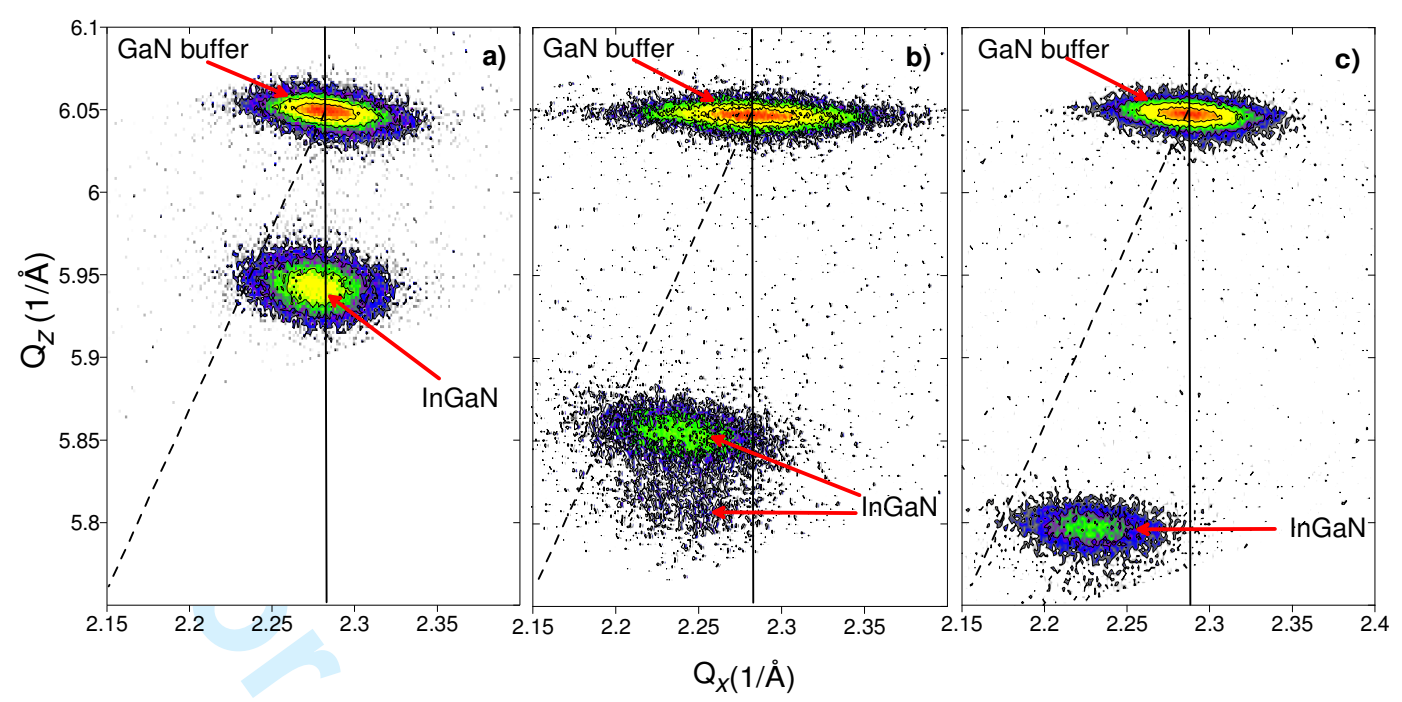

Figure 5. 
a)

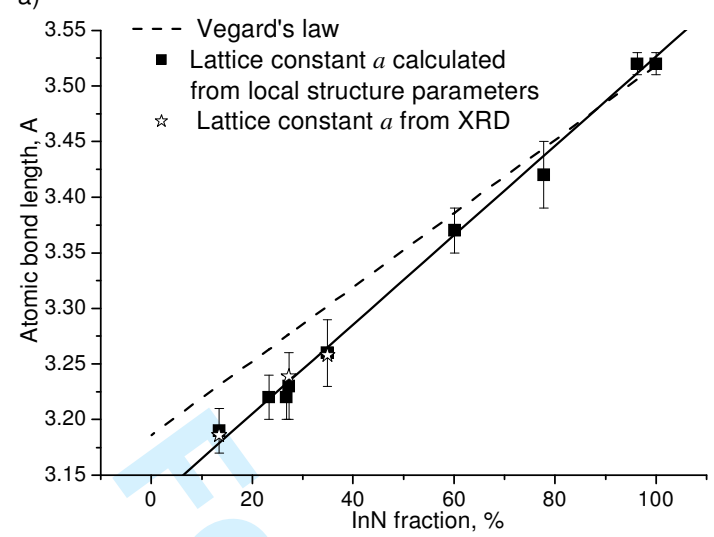

b)

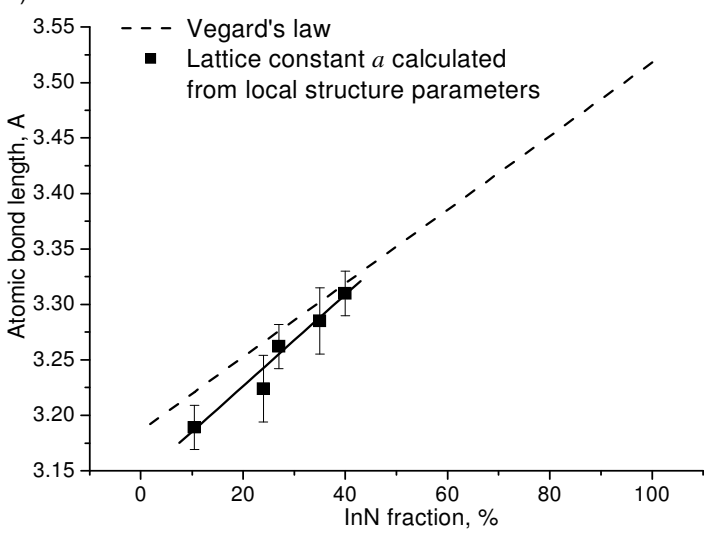

Figure 6. 
Table I. Local structure parameters for MBE grown InGaN epilayers.

\begin{tabular}{|c|c|c|c|c|c|c|c|}
\hline InN content, $\%$ & $\begin{array}{c}\text { Element and } \\
\text { detection mode }\end{array}$ & $\begin{array}{l}\text { Atom } \\
\text { type }\end{array}$ & $\begin{array}{l}\text { Number } \\
\text { of atoms }\end{array}$ & Distance, $\AA$ & $\begin{array}{l}\text { Debye-Waller } \\
\text { factor, } \AA\end{array}$ & $k$ range, $\AA^{-1}$ & $\begin{array}{l}\text { Fit index } \\
\qquad \mathrm{R}\end{array}$ \\
\hline 100 & In K-edge FLY & $\begin{array}{l}\mathrm{N} \\
\mathrm{In}\end{array}$ & $\begin{array}{c}4 \\
12\end{array}$ & $\begin{array}{l}2.15 \pm 0.02 \\
3.52 \pm 0.01\end{array}$ & $\begin{array}{l}0.007 \\
0.013\end{array}$ & $2-15$ & 29.30 \\
\hline 96.3 & In K-edge FLY & $\begin{array}{l}\mathrm{N} \\
\mathrm{In}\end{array}$ & $\begin{array}{c}4 \\
12\end{array}$ & $\begin{array}{l}2.15 \pm 0.02 \\
3.52 \pm 0.01\end{array}$ & $\begin{array}{l}0.006 \\
0.014\end{array}$ & $2-11$ & 28.78 \\
\hline \multirow{3}{*}{77.8} & In K-edge FLY & $\begin{array}{c}\mathrm{N} \\
\mathrm{Ga} \\
\mathrm{In}\end{array}$ & $\begin{array}{c}4 \\
3.4 \pm 1.0 \\
8.6 \pm 1.0\end{array}$ & $\begin{array}{l}2.14 \pm 0.02 \\
3.41 \pm 0.05 \\
3.45 \pm 0.02\end{array}$ & $\begin{array}{l}0.010 \\
0.021 \\
0.021\end{array}$ & $1.5-11$ & 30.69 \\
\hline & In K-edge TEY & $\begin{array}{c}\mathrm{N} \\
\mathrm{Ga} \\
\mathrm{In}\end{array}$ & $\begin{array}{c}4 \\
4.0 \pm 1.8 \\
8.0 \pm 1.8\end{array}$ & $\begin{array}{l}2.12 \pm 0.02 \\
3.39 \pm 0.06 \\
3.44 \pm 0.02\end{array}$ & $\begin{array}{l}0.015 \\
0.023 \\
0.023 \\
\end{array}$ & $1.7-11$ & 43.90 \\
\hline & Ga K-edge TEY & $\begin{array}{c}\mathrm{N} \\
\mathrm{Ga} \\
\mathrm{In}\end{array}$ & $\begin{array}{c}4 \\
3.1 \pm 1.8 \\
8.9 \pm 1.8 \\
\end{array}$ & $\begin{array}{l}1.98 \pm 0.02 \\
3.31 \pm 0.07 \\
3.42 \pm 0.03\end{array}$ & $\begin{array}{l}0.014 \\
0.023 \\
0.023 \\
\end{array}$ & $2.5-13$ & 35.94 \\
\hline \multirow{3}{*}{60.1} & In K-edge FLY & $\begin{array}{c}\mathrm{N} \\
\mathrm{Ga} \\
\mathrm{In} \\
\end{array}$ & $\begin{array}{c}4 \\
4.3 \pm 0.9 \\
7.7 \pm 0.9\end{array}$ & $\begin{array}{l}2.13 \pm 0.01 \\
3.37 \pm 0.02 \\
3.43 \pm 0.01\end{array}$ & $\begin{array}{l}0.010 \\
0.017 \\
0.017 \\
\end{array}$ & $2-11$ & 30.58 \\
\hline & In K-edge TEY & $\begin{array}{c}\mathrm{N} \\
\mathrm{Ga} \\
\mathrm{In}\end{array}$ & $\begin{array}{c}4 \\
4.0 \pm 0.6 \\
8.0 \pm 0.6\end{array}$ & $\begin{array}{l}2.13 \pm 0.01 \\
3.38 \pm 0.03 \\
3.42 \pm 0.01\end{array}$ & $\begin{array}{l}0.006 \\
0.017 \\
0.017\end{array}$ & $2-11$ & 29.78 \\
\hline & Ga K-edge TEY & $\begin{array}{c}\mathrm{N} \\
\mathrm{Ga} \\
\mathrm{In} \\
\end{array}$ & $\begin{array}{c}4 \\
6.0 \pm 1.3 \\
6.0 \pm 1.3\end{array}$ & $\begin{array}{l}1.97 \pm 0.02 \\
3.30 \pm 0.03 \\
3.36 \pm 0.03\end{array}$ & $\begin{array}{l}0.016 \\
0.020 \\
0.020 \\
\end{array}$ & $2.5-11$ & 38.37 \\
\hline \multirow{2}{*}{34.9} & In K-edge FLY & $\begin{array}{l}\mathrm{N} \\
\mathrm{Ga} \\
\mathrm{In}\end{array}$ & $\begin{array}{c}4 \\
7.0 \pm 0.8 \\
5.0 \pm 0.8\end{array}$ & $\begin{array}{l}2.10 \pm 0.01 \\
3.30 \pm 0.02 \\
3.32 \pm 0.03\end{array}$ & $\begin{array}{l}0.006 \\
0.017 \\
0.017\end{array}$ & $1.7-11$ & 34.20 \\
\hline & Ga K-edge TEY & $\begin{array}{l}\mathrm{N} \\
\mathrm{Ga} \\
\mathrm{In}\end{array}$ & $\begin{array}{c}4 \\
9.4 \pm 0.7 \\
2.6 \pm 0.7\end{array}$ & $\begin{array}{l}1.93 \pm 0.01 \\
3.21 \pm 0.01 \\
3.24 \pm 0.03\end{array}$ & $\begin{array}{l}0.004 \\
0.015 \\
0.015\end{array}$ & $2.5-13$ & 27.08 \\
\hline \multirow{3}{*}{27.3} & In K-edge FLY & $\begin{array}{c}\mathrm{N} \\
\mathrm{Ga} \\
\mathrm{In} \\
\end{array}$ & $\begin{array}{c}4 \\
8.1 \pm 0.9 \\
3.9 \pm 0.9 \\
\end{array}$ & $\begin{array}{l}2.09 \pm 0.02 \\
3.28 \pm 0.02 \\
3.32 \pm 0.03\end{array}$ & $\begin{array}{l}0.005 \\
0.018 \\
0.018 \\
\end{array}$ & $1.8-11$ & 33.61 \\
\hline & In K-edge TEY & $\begin{array}{c}\mathrm{N} \\
\mathrm{Ga} \\
\mathrm{In} \\
\end{array}$ & $\begin{array}{c}4 \\
9.2 \pm 1.8 \\
2.8 \pm 1.8\end{array}$ & $\begin{array}{l}2.08 \pm 0.02 \\
3.26 \pm 0.02 \\
3.33 \pm 0.09\end{array}$ & $\begin{array}{l}0.014 \\
0.019 \\
0.019 \\
\end{array}$ & $1.7-10.5$ & 42.48 \\
\hline & Ga K-edge TEY & $\begin{array}{c}\mathrm{N} \\
\mathrm{Ga} \\
\mathrm{In} \\
\end{array}$ & $\begin{array}{c}4 \\
9.4 \pm 1.1 \\
2.6 \pm 1.1 \\
\end{array}$ & $\begin{array}{l}1.94 \pm 0.01 \\
3.19 \pm 0.01 \\
3.19 \pm 0.03\end{array}$ & $\begin{array}{l}0.006 \\
0.015 \\
0.015 \\
\end{array}$ & $2.5-13$ & 31.39 \\
\hline \multirow{3}{*}{26.8} & In K-edge FLY & $\begin{array}{l}\mathrm{N} \\
\mathrm{Ga} \\
\mathrm{In}\end{array}$ & $\begin{array}{c}4 \\
8.0 \pm 0.9 \\
4.0 \pm 0.9\end{array}$ & $\begin{array}{l}2.10 \pm 0.01 \\
3.27 \pm 0.02 \\
3.31 \pm 0.02\end{array}$ & $\begin{array}{l}0.006 \\
0.017 \\
0.017\end{array}$ & $1.7-11$ & 27.89 \\
\hline & In K-edge TEY & $\begin{array}{c}\mathrm{N} \\
\mathrm{Ga} \\
\mathrm{In}\end{array}$ & $\begin{array}{c}4 \\
9.3 \pm 1.7 \\
2.7 \pm 1.7\end{array}$ & $\begin{array}{l}2.08 \pm 0.02 \\
3.27 \pm 0.03 \\
3.33 \pm 0.08\end{array}$ & $\begin{array}{l}0.009 \\
0.024 \\
0.024\end{array}$ & $2-11$ & 41.59 \\
\hline & Ga K-edge TEY & $\begin{array}{c}\mathrm{N} \\
\mathrm{Ga} \\
\mathrm{In} \\
\end{array}$ & $\begin{array}{c}4 \\
9.8 \pm 1.0 \\
2.2 \pm 1.0 \\
\end{array}$ & $\begin{array}{l}1.94 \pm 0.02 \\
3.18 \pm 0.02 \\
3.21 \pm 0.06\end{array}$ & $\begin{array}{l}0.011 \\
0.013 \\
0.013 \\
\end{array}$ & $2.5-12$ & 33.33 \\
\hline \multirow{3}{*}{23.3} & In K-edge FLY & $\begin{array}{c}\mathrm{N} \\
\mathrm{Ga} \\
\mathrm{In}\end{array}$ & $\begin{array}{c}4 \\
10.3 \pm 1.5 \\
1.7 \pm 1.5\end{array}$ & $\begin{array}{l}2.08 \pm 0.02 \\
3.27 \pm 0.02 \\
3.30 \pm 0.07\end{array}$ & $\begin{array}{l}0.005 \\
0.023 \\
0.023\end{array}$ & $1.5-11$ & 36.92 \\
\hline & In K-edge TEY & $\begin{array}{c}\mathrm{N} \\
\mathrm{Ga} \\
\mathrm{In} \\
\end{array}$ & $\begin{array}{c}4 \\
10.6 \pm 1.2 \\
1.4 \pm 1.2 \\
\end{array}$ & $\begin{array}{l}2.07 \pm 0.01 \\
3.25 \pm 0.02 \\
3.30 \pm 0.30 \\
\end{array}$ & $\begin{array}{l}0.014 \\
0.022 \\
0.022 \\
\end{array}$ & $1.7-10$ & 38.94 \\
\hline & Ga K-edge TEY & $\begin{array}{c}\mathrm{N} \\
\mathrm{Ga} \\
\mathrm{In} \\
\end{array}$ & $\begin{array}{c}4 \\
8.9 \pm 0.2 \\
3.1 \pm 0.2 \\
\end{array}$ & $\begin{array}{l}1.94 \pm 0.03 \\
3.20 \pm 0.01 \\
3.20 \pm 0.02\end{array}$ & $\begin{array}{l}0.003 \\
0.007 \\
0.007 \\
\end{array}$ & $2.5-13$ & 37.25 \\
\hline \multirow{2}{*}{13.5} & In K-edge FLY & $\begin{array}{c}\mathrm{N} \\
\mathrm{Ga}\end{array}$ & $\begin{array}{c}4 \\
12 \\
\end{array}$ & $\begin{array}{l}2.08 \pm 0.02 \\
3.25 \pm 0.02 \\
\end{array}$ & $\begin{array}{l}0.012 \\
0.024 \\
\end{array}$ & $1.5-11$ & 47.00 \\
\hline & Ga K-edge TEY & $\begin{array}{c}\mathrm{N} \\
\mathrm{Ga}\end{array}$ & $\begin{array}{c}4 \\
12 \\
\end{array}$ & $\begin{array}{l}1.93 \pm 0.02 \\
3.18 \pm 0.01 \\
\end{array}$ & $\begin{array}{l}0.008 \\
0.015 \\
\end{array}$ & $2.5-13$ & 34.42 \\
\hline
\end{tabular}


Table II. Local structure parameters for InGaN samples grown by MOCVD.

\begin{tabular}{|c|c|c|c|c|c|c|c|}
\hline InN content, $\%$ & $\begin{array}{c}\text { Element and } \\
\text { detection mode }\end{array}$ & $\begin{array}{l}\text { Atom } \\
\text { type }\end{array}$ & $\begin{array}{l}\text { Number } \\
\text { of atoms }\end{array}$ & Distance, $\AA$ & $\begin{array}{l}\text { Debye-Waller } \\
\text { factor, } \AA^{2}\end{array}$ & $k$ range, $\AA^{-1}$ & $\begin{array}{c}\text { Fit index } \\
\mathrm{R}\end{array}$ \\
\hline \multirow{3}{*}{40} & In K-edge FLY & $\begin{array}{c}\mathrm{N} \\
\mathrm{Ga} \\
\mathrm{In}\end{array}$ & $\begin{array}{c}4 \\
7.2 \pm 0.6 \\
4.8 \pm 0.6\end{array}$ & $\begin{array}{l}2.12 \pm 0.01 \\
3.31 \pm 0.02 \\
3.37 \pm 0.02\end{array}$ & $\begin{array}{l}0.007 \\
0.018 \\
0.018\end{array}$ & $1.5-11$ & 25.12 \\
\hline & In K-edge TEY & $\begin{array}{c}\mathrm{N} \\
\mathrm{Ga} \\
\mathrm{In} \\
\end{array}$ & $\begin{array}{c}4 \\
6.7 \pm 1.7 \\
5.3 \pm 1.7 \\
\end{array}$ & $\begin{array}{l}2.11 \pm 0.01 \\
3.33 \pm 0.03 \\
3.39 \pm 0.03 \\
\end{array}$ & $\begin{array}{l}0.006 \\
0.020 \\
0.020 \\
\end{array}$ & $2-12$ & 40.20 \\
\hline & $\begin{array}{l}\text { Ga K-edge } \\
\text { TEY }\end{array}$ & $\begin{array}{c}\mathrm{N} \\
\mathrm{Ga} \\
\mathrm{In}\end{array}$ & $\begin{array}{c}4 \\
8.1 \pm 1.2 \\
3.9 \pm 1.2\end{array}$ & $\begin{array}{l}1.95 \pm 0.03 \\
3.24 \pm 0.01 \\
3.31 \pm 0.03\end{array}$ & $\begin{array}{l}0.003 \\
0.013 \\
0.013\end{array}$ & $2.5-11$ & 33.73 \\
\hline \multirow{3}{*}{35} & In K-edge FLY & $\begin{array}{c}\mathrm{N} \\
\mathrm{Ga} \\
\mathrm{In}\end{array}$ & $\begin{array}{c}4 \\
8.0 \pm 0.8 \\
4.0 \pm 0.8\end{array}$ & $\begin{array}{l}2.12 \pm 0.01 \\
3.30 \pm 0.02 \\
3.35 \pm 0.03\end{array}$ & $\begin{array}{l}0.008 \\
0.019 \\
0.019\end{array}$ & $1.5-11$ & 28.05 \\
\hline & In K-edge TEY & $\begin{array}{c}\mathrm{N} \\
\mathrm{Ga} \\
\mathrm{In}\end{array}$ & $\begin{array}{c}4 \\
7.1 \pm 2.0 \\
4.9 \pm 2.0\end{array}$ & $\begin{array}{l}2.12 \pm 0.01 \\
3.31 \pm 0.04 \\
3.35 \pm 0.03\end{array}$ & $\begin{array}{l}0.008 \\
0.022 \\
0.022 \\
\end{array}$ & $2-10.5$ & 40.97 \\
\hline & $\begin{array}{c}\text { Ga K-edge } \\
\text { TEY }\end{array}$ & $\begin{array}{c}\mathrm{N} \\
\mathrm{Ga} \\
\mathrm{In} \\
\end{array}$ & $\begin{array}{c}4 \\
8.7 \pm 0.8 \\
3.3 \pm 0.8\end{array}$ & $\begin{array}{l}1.95 \pm 0.01 \\
3.25 \pm 0.02 \\
3.27 \pm 0.03\end{array}$ & $\begin{array}{l}0.008 \\
0.015 \\
0.015\end{array}$ & $2.5-11$ & 24.73 \\
\hline \multirow{3}{*}{27} & In K-edge FLY & $\begin{array}{c}\mathrm{N} \\
\mathrm{Ga} \\
\mathrm{In}\end{array}$ & $\begin{array}{c}4 \\
8.1 \pm 0.7 \\
3.9 \pm 0.7\end{array}$ & $\begin{array}{l}2.11 \pm 0.01 \\
3.29 \pm 0.02 \\
3.35 \pm 0.02\end{array}$ & $\begin{array}{l}0.008 \\
0.017 \\
0.017\end{array}$ & $1.5-11$ & 27.98 \\
\hline & In K-edge TEY & $\begin{array}{c}\mathrm{N} \\
\mathrm{Ga} \\
\mathrm{In}\end{array}$ & $\begin{array}{c}4 \\
9.0 \pm 2.3 \\
3.0 \pm 2.3\end{array}$ & $\begin{array}{l}2.09 \pm 0.02 \\
3.28 \pm 0.04 \\
3.31 \pm 0.08\end{array}$ & $\begin{array}{l}0.010 \\
0.024 \\
0.024\end{array}$ & $2-10.5$ & 36.77 \\
\hline & $\begin{array}{l}\text { Ga K-edge } \\
\text { TEY }\end{array}$ & $\begin{array}{c}\mathrm{N} \\
\mathrm{Ga} \\
\mathrm{In}\end{array}$ & $\begin{array}{c}4 \\
9.1 \pm 0.6 \\
2.9 \pm 0.6\end{array}$ & $\begin{array}{l}1.95 \pm 0.02 \\
3.23 \pm 0.01 \\
3.24 \pm 0.02\end{array}$ & $\begin{array}{l}0.010 \\
0.012 \\
0.012 \\
\end{array}$ & $2.5-12$ & 31 \\
\hline \multirow{3}{*}{24} & In K-edge FLY & $\begin{array}{c}\mathrm{N} \\
\mathrm{Ga} \\
\mathrm{In} \\
\end{array}$ & $\begin{array}{c}4 \\
8.6 \pm 1.3 \\
3.4 \pm 1.3\end{array}$ & $\begin{array}{l}2.09 \pm 0.01 \\
3.27 \pm 0.02 \\
3.33 \pm 0.06\end{array}$ & $\begin{array}{l}0.004 \\
0.021 \\
0.021 \\
\end{array}$ & $1.5-11$ & 33.57 \\
\hline & In K-edge TEY & $\begin{array}{c}\mathrm{N} \\
\mathrm{Ga} \\
\mathrm{In}\end{array}$ & $\begin{array}{c}4 \\
9.4 \pm 2.2 \\
2.6 \pm 2.2\end{array}$ & $\begin{array}{l}2.07 \pm 0.03 \\
3.27 \pm 0.03 \\
3.31 \pm 0.06\end{array}$ & $\begin{array}{l}0.027 \\
0.021 \\
0.007 \\
\end{array}$ & $1.7-12$ & 57.74 \\
\hline & $\begin{array}{l}\text { Ga K-edge } \\
\text { TEY }\end{array}$ & $\begin{array}{c}\mathrm{N} \\
\mathrm{Ga} \\
\mathrm{In}\end{array}$ & $\begin{array}{c}4 \\
9.8 \pm 0.7 \\
2.2 \pm 0.7\end{array}$ & $\begin{array}{l}1.95 \pm 0.02 \\
3.21 \pm 0.01 \\
3.21 \pm 0.03\end{array}$ & $\begin{array}{l}0.010 \\
0.012 \\
0.012 \\
\end{array}$ & $2.5-12.5$ & 28.89 \\
\hline \multirow{2}{*}{10.5} & In K-edge FLY & $\begin{array}{c}\mathrm{N} \\
\mathrm{Ga}\end{array}$ & $\begin{array}{c}4 \\
12\end{array}$ & $\begin{array}{l}2.10 \pm 0.01 \\
3.23 \pm 0.02\end{array}$ & $\begin{array}{l}0.005 \\
0.013\end{array}$ & $1.5-11$ & 31.35 \\
\hline & $\begin{array}{c}\text { Ga K-edge } \\
\text { TEY }\end{array}$ & $\begin{array}{c}\mathrm{N} \\
\mathrm{Ga}\end{array}$ & $\begin{array}{c}4 \\
12\end{array}$ & $\begin{array}{l}1.94 \pm 0.02 \\
3.18 \pm 0.02\end{array}$ & $\begin{array}{l}0.004 \\
0.013\end{array}$ & $2.5-13$ & 37.31 \\
\hline
\end{tabular}



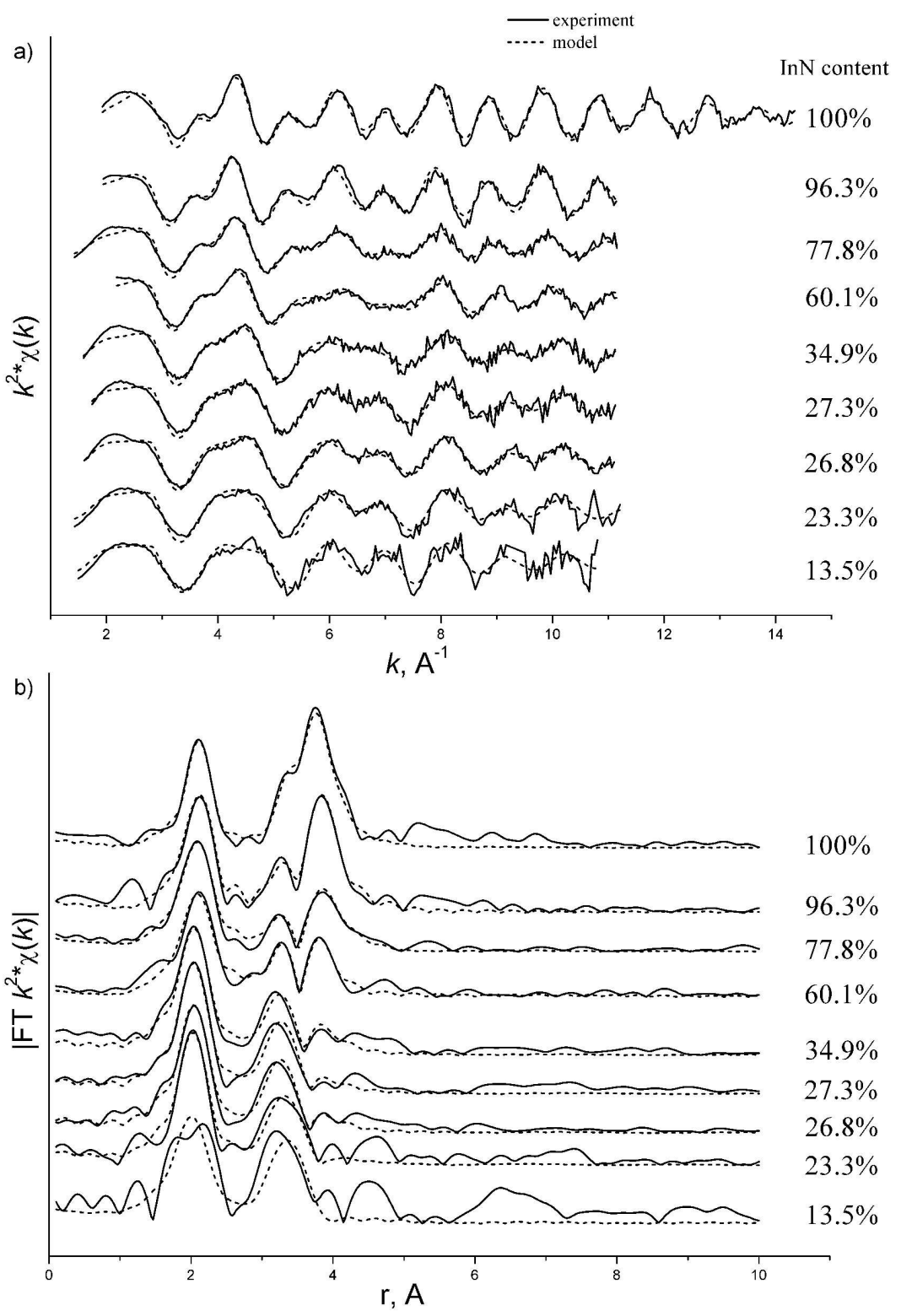

$594 \times 839 \mathrm{~mm}(150 \times 150 \mathrm{DPI})$

http://mc.manuscriptcentral.com/pm-pml 